\title{
RELACIONES DE INTERACCIÓN ENTRE ANTOFAGASTA DE LA SIERRA Y EL VALLE DEL BOLSÓN (CATAMARCA, ARGENTINA). PRIMEROS APORTES DESDE LA ALFARERÍA CA. 900-1600 D.C.
}

\author{
RELATIONSHIPS OF INTERACTION BETWEEN ANTOFAGASTA DE LA \\ SIERRA AND THE BOLSON VALLEY (CATAMARCA, ARGENTINA). FIRST \\ CONTRIBUTIONS FROM POTTERY CA. AD 900-1600
}

\author{
Verónica Puente ${ }^{1}$
}

\begin{abstract}
Se aborda el problema de las prácticas de producción alfarera entre ca. 900-1600 d.C. como mecanismo para estudiar relaciones de interacción social y dinámicas locales en y entre asentamientos emplazados en ambientes diferenciados: valle y puna. Específicamente se compara la información generada sobre el valle del Bolsón (Belén) y la cuenca del río Las Pitas (puna meridional, Antofagasta de la Sierra), Catamarca, Argentina. La interacción entre ambas regiones fue registrada a partir de distintas líneas de evidencia demostrando una historia vinculada. Se presentan los primeros resultados obtenidos a partir del análisis tecnológico y estético de los conjuntos cerámicos. Se propone la circulación de ciertas piezas y de ideas materializadas en estilos, recursos estilísticos y patrones estéticos. A partir de ello, se sugiere que los alfareros de Antofagasta elaboraron su cerámica combinando recursos estilísticos presentes en la cerámica del área valliserrana del noroeste argentino pero con técnicas propias y materias primas locales.

Palabras claves: interacción, alfarería, tardío prehispánico.
\end{abstract}

The issue of pottery production practices between ca. AD 900-1,600 as a mechanism to study relations of social interaction and local dynamics within and between settlements located in different environments (valley and puna) is addressed. Specifically, the information generated on the Bolsón Valley (Belén) and Las Pitas river basin (southern puna, Antofagasta de la Sierra), Catamarca, Argentina is compared. The interaction between the two regions was recorded from different lines of evidence demonstrating a bound history. The first results obtained from the analysis of technological and aesthetic ceramic assemblages are presented. The circulation of certain vessels as well as of ideas materialized in styles, stylistic resources and aesthetic standards is proposed. As a result, it is suggested that the potters of Antofagasta made their pottery by combining stylistic resources present in the ceramics of the Valliserrana area of northwestern Argentina but using their own techniques and local raw materials.

Key words: Interaction, pottery, prehispanic late.

Se aborda el problema de las prácticas de producción alfarera durante el tardío prehispánico (ca. 900-1.600 d.C.) en el noroeste argentino (NOA) como mecanismo en donde estudiar relaciones de interacción social y dinámicas locales en y entre asentamientos emplazados en ambientes de producción diferenciada: valle y puna. Específicamente se comparan aspectos estéticos y tecnológicos de los conjuntos cerámicos recuperados en el valle del Bolsón (Belén, Catamarca) y en la cuenca del río Las Pitas (puna meridional, Antofagasta de la Sierra, Catamarca) (Figura 1).

Este problema se inserta dentro del tema de las interacciones interregionales en los Andes del sur. Se plantea al período "Tardío" o "Desarrollos Regionales" como un momento de cambios y transformaciones manifestados en el surgimiento de grandes poblados aglutinados, crecimiento demográfico, intensificación agrícola, estilos iconográficos regionales, etc., y caracterizado por instancias de conflicto e integración interregional entre distintos sistemas sociopolíticos (Nielsen 2001; Núñez Regueiro 1974; Tarragó 2000). Actualmente se debate sobre la organización política que operó en estos contextos de cambio: jefaturas con cabeceras políticas emplazadas en los valles y colonias dependientes ubicadas en distintos pisos ecológicos (Tarragó 2000), sociedades corporativas

1 CONICET, Laboratorio de Arqueología, Universidad Nacional de Mar del Plata, Mar del Plata, Argentina. vpuente78@yahoo.com.ar 

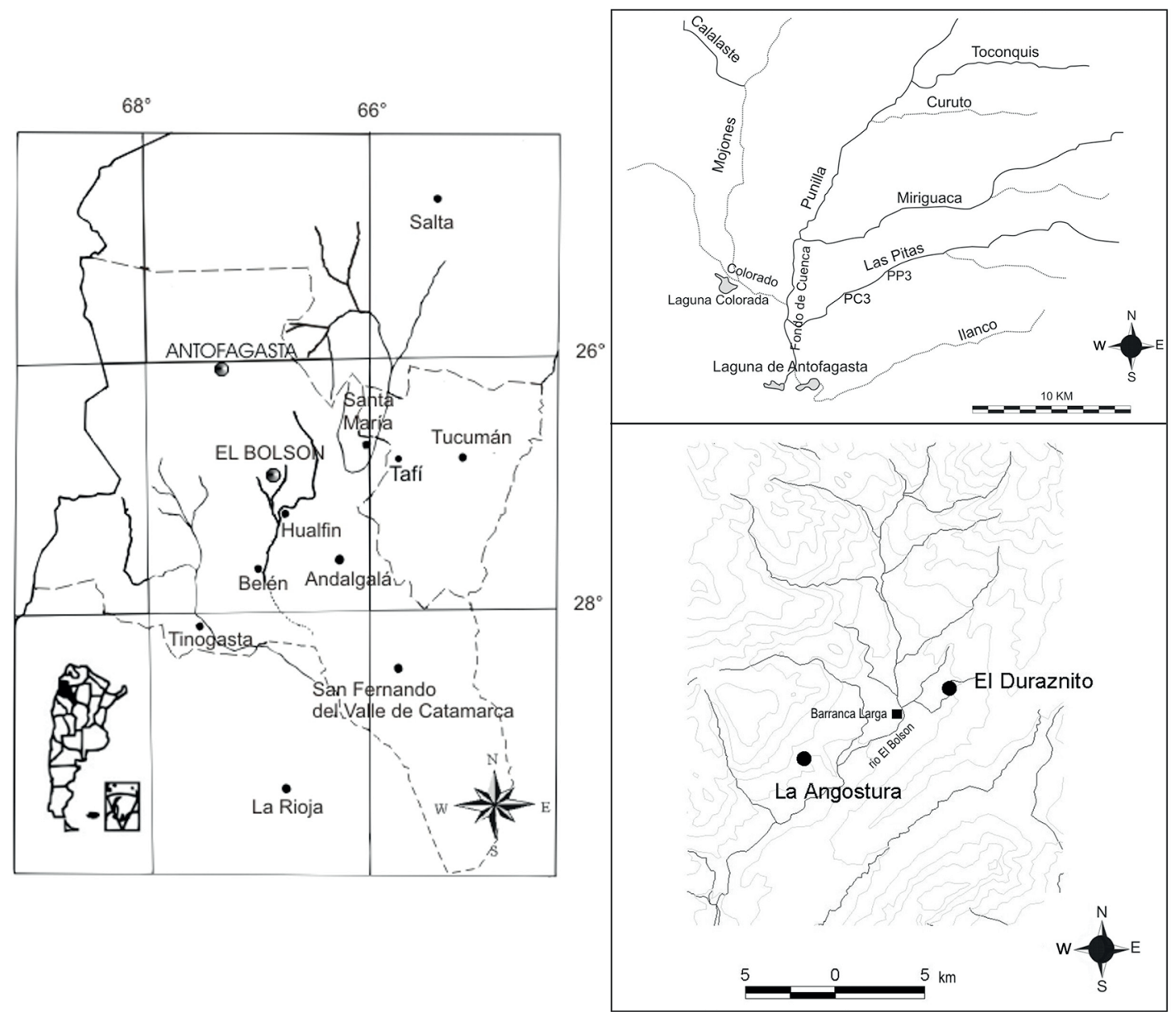

Figura 1. Mapa regional. Modificado de Quiroga (2011) y Cohen (2010).

Regional map. Modified from Quiroga (2011) and Cohen (2010).

(Nielsen 2006) o integración comunal (Acuto 2007). El modelo de jefatura sostiene que las elites controlaron la producción y/o circulación interregional de bienes y entre los mecanismos utilizados para consolidar su poder se encontró la imposición de estilos iconográficos estructurados y de amplia distribución (Tarragó 2000). Más allá de las diferencias políticas entre dichas propuestas, hay evidencias de que coexistieron múltiples modos de interacción interregional simultáneos y de larga tradición temporal, entre ellos el tráfico caravanero (Núñez y Dillehay 1979), los ejes económicos interfamiliares (Aschero 2000), y el tráfico incorporado (Nielsen 2006). La interacción propiciada por el tráfico de caravanas acorta las distancias recorridas en relación con períodos anteriores (Núñez y Dillehay 1979). Sin embargo, hay patrones de diseños que se replican a largas distancias y en distintos soportes, lo que da cuenta de códigos compartidos entre regiones distantes (Aschero 2000). En este sentido, durante este período coexistieron distintos mecanismos de circulación de información, personas y objetos que operaron por distintos motivos y a distancias disímiles.

Las relaciones de interacción entre Antofagasta de la Sierra (ANS) y los valles del oeste catamarqueño para este lapso temporal fueron registradas a partir de distintos ítems materiales: arquitectura, estilos cerámicos, iconografía, arte rupestre, obsidianas, etc. (Aschero 2000; Elías y Escola 2008; Olivera et al. 2003-2005; Podestá y Olivera 2006; Quiroga 2011; Raffino y Cigliano 1973; Tarragó et al. 
1997; entre otros). En 1970 Raffino y Cigliano plantearon la existencia de relaciones entre el sitio La Alumbrera -situado en el fondo de cuenca del río Punilla, recurso hídrico principal de ANS- y emplazamientos ubicados en valles de las provincias de Catamarca y La Rioja que según los autores estaban bajo el "dominio de la Cultura Belén" (Raffino y Cigliano 1973:249). Olivera y coautores (20032005) destacan la presencia de relaciones intensas entre el fondo de cuenca mencionado y los valles de Hualfín y Abaucán (Catamarca) para momentos tardíos e incaicos a partir de la evidencia material de los sitios La Alumbrera y Bajo del Coypar II (ANS), entre las que destacan la cerámica Belén y Belén-Inca. Más allá de la referencia sobre la presencia de estos estilos, la cerámica no fue un indicador estudiado para discutir las relaciones de interacción entre ambas regiones.

El objetivo de este trabajo es realizar un aporte inicial al estudio de la circulación de objetos, saberes y personas entre el valle del Bolsón y la cuenca del río Las Pitas (sector intermedio de ANS) a partir de una perspectiva que contempla en forma interrelacionada los aspectos estéticos visuales de las piezas y las características de sus pastas. Estos indicadores permiten analizar la relación entre lo que el artesano produjo, el modo en que lo hizo y los materiales que utilizó, y contribuyen a responder si ¿circularon las piezas, los estilos, los recursos estilísticos o tradiciones de manufactura?, ¿se reconocen patrones estéticos y tecnológicos compartidos o diferenciados entre ambas regiones?

Las prácticas de producción alfarera postformativas en el valle del Bolsón han sido estudiadas de manera intensiva (Puente 2011). A diferencia de ello, los estudios sistemáticos sobre alfarería del tardío en ANS aún son escasos. Se cuenta con análisis funcionales realizados sobre materiales de Bajo del Coypar II (Vigliani 2005). En la quebrada de Miriguaca (sector intermedio de ANS), subsidiaria al fondo de cuenca del río Punilla, la tecnología cerámica se está investigando a partir de los conjuntos obtenidos en el sitio Corral Alto (Gasparoti 2012) (Figura 1). Este trabajo es el primer aporte sobre conjuntos cerámicos en la cuenca del río Las Pitas para este lapso temporal. Los resultados alcanzados constituyen un avance preliminar para discutir las modalidades de interacción entre regiones que evidencian desde numerosas líneas de análisis un pasado vinculado.

\section{Categorías de Análisis}

La interacción interregional puede darse en forma de circulación de personas, objetos y saberes. Más allá de la modalidad que adquiera dicha interacción en contextos sociohistóricos particulares, se trata de una práctica social donde se crean, reproducen y transforman relaciones y lazos sociales y en la que se articulan aspectos materiales y simbólicos (Bauer y Davies 2010; Lazzari 1999). Diferentes objetos y saberes pueden circular de modos distintos y a distancias disímiles generando así un entramado de paisajes sociales particulares que serán incorporados de distinto modo en la vida cotidiana de los agentes involucrados en la interacción (Lazzari 1999). Debido a que la cultura material mediatiza, genera y objetiva interacciones sociales es posible estudiar dichas relaciones a partir del examen de similitudes y diferencias en la naturaleza contextual y material de los objetos (Jones 2002; Shanks y Tilley 1987). En este sentido, el estudio de la estética visual de las piezas cerámicas, de su tecnología de elaboración y de las materias primas utilizadas permite conocer, por un lado, las prácticas de producción alfarera local y, por otro, discutir las formas que adquirió la interacción a escalas amplias.

Se entiende a la tecnología y a la estética de los objetos como prácticas resultado de procesos en los que se imbrican elecciones, relaciones y representaciones sociales (Gosden 2001; Lemonnier 1992). Los alfareros producen las piezas combinando las materias primas disponibles, saberes tradicionales y modos de hacer particulares. Es por ello que la tecnología constituye un conjunto de decisiones que trascienden el mero propósito funcional (Lemonnier 1992). Las tradiciones de manufactura son elecciones o modos de hacer particulares compartidos por un grupo de personas y que perduran más de una generación (Gosselain 1998).

El concepto de estética utilizado en este trabajo proviene de la "Antropología del Arte" y se la concibe como una práctica perceptiva situada en un contexto histórico cultural específico. De este modo, la significación y el efecto estético que las personas generan a partir de la percepción de los objetos son construcciones sociales que trascienden al objeto en sí (Gell 1998; Gosden 2001). Particularmente, en este escrito se hará referencia a la estética visual, es decir, si las vasijas estudiadas se perciben o no como semejantes a partir de los recursos estilísticos utilizados por los alfareros para generar sus cualidades 
formales: color, forma, brillo, tamaño, diseño, etc. Dichas cualidades generan en las personas experiencias sensoriales, es decir, efectos estéticos en donde se objetivan, mediatizan y experimentan las relaciones sociales y las ideas.

De este modo, el concepto de estética se diferencia del de estilo. Aquí se utiliza esta última categoría para hacer referencia a los estilos regionales que fueron tradicionalmente definidos para el NOA como unidades delimitadas a partir de un conjunto de elementos que, más allá de cierta variabilidad, reproducen de forma constante determinadas variedades morfológicas, color e iconografía.

En síntesis, la apariencia final de las vasijas es el resultado de la mixtura de intereses estéticos y tecnológicos individuales y de categorías compartidas por el grupo social de pertenencia. Dichas decisiones tienen un correlato material. El análisis interrelacionado de las líneas de evidencia mencionadas permite discutir si la interacción social entre el valle del Bolsón y la cuenca del río Las Pitas (ANS) implicó la circulación de objetos, tradiciones de manufactura, estilos o patrones estéticos. Este trabajo constituye una primera aproximación al tema.

\section{Perspectiva Metodológica}

Para discutir si circularon los objetos, los saberes o ambos es imprescindible analizar la relación entre lo que el artesano produjo y el modo en que lo hizo. Esto requiere de un abordaje integrado de la estética visual de los objetos, la tecnología de elaboración y las materias primas utilizadas.

Para analizar la estética visual se procuró definir la variabilidad morfológica, tratamientos de superficie, color, representaciones y técnicas plásticas de la cerámica presente en cada sitio y región. En primer lugar los fragmentos fueron reunidos en grupos de referencia generales y se analizó la variabilidad contenida en cada uno de ellos. De este modo se intentó definir la apariencia visual de las vasijas y su variabilidad regional por medio del estudio de los recursos estilísticos utilizados por los alfareros en el pasado (Sheppard 1957). Debido a que los restos cerámicos recuperados son fragmentarios, la información recabada al respecto es diversa y depende del grado de conservación diferencial en cada sitio.

Para estudiar las materias primas y la tecnología de elaboración de las vasijas se analizaron las pastas cerámicas. Todos los fragmentos recuperados en los sitios cuyo tamaño superaba los $2 \mathrm{~cm}$ de lado fueron analizados en corte fresco por lupa binocular. Este análisis permitió clasificar la muestra en grupos generales de pastas, a partir de los cuales se seleccionaron casos para estudios petrográficos con microscopio de luz polarizada. Cada uno de los fragmentos seleccionados perteneció a una pieza diferente, por tal motivo en esta instancia de investigación la unidad de análisis pasó de ser el fragmento a la pieza como ejemplar. La petrografía permite obtener información acerca de los modos de elaboración de las pastas y la composición de las inclusiones no plásticas. Las variables observadas son: matriz, porosidad, inclusiones no plásticas (naturaleza, tamaño, esfericidad y redondez). Se realizó un análisis modal del tipo de antiplástico, densidad y porosidad de las pastas por un conteo aproximado de 400 puntos a distancias constantes por corte delgado (Cremonte 1996; Stoltman 2001).

Esta información fue relacionada con la obtenida del estudio de los atributos visuales para evaluar la existencia de asociaciones entre ellos. Se analizó si piezas similares en su morfología, color y tratamiento superficial fueron manufacturadas con técnicas o con materias primas diferentes y viceversa, si piezas diferentes según sus características visuales fueron elaboradas de modo similar.

Para el valle del Bolsón se cuenta con estudios de procedencia. Análisis petrológicos (comparación de la petrografía de arenas locales y la petrografía cerámica) y por AANI permitieron identificar que la mayoría de la cerámica recuperada en $\mathrm{La}$ Angostura y El Duraznito fue elaborada con materias primas locales (Puente 2011; Puente et al. 2014). A diferencia de ello, los estudios de procedencia sobre la cerámica de Las Pitas se encuentran en proceso de análisis. Hasta el momento se analizaron por petrografía distintos depósitos de arena de la región y fueron comparados con la petrografía cerámica, obteniendo resultados aún preliminares.

En síntesis, el estudio integrado de la estética visual, la tecnología y las materias primas permite conocer un número importante de elecciones realizadas por los alfareros en el proceso de elaboración y, de este modo, identificar modos de hacer particulares como así también patrones de elecciones compartidas por distintos artesanos.

\section{Casos de Análisis}

El rango temporal 900-1600 d.C. integra a los períodos de Desarrollos Regionales, Inca e Hispano 
indígena (Núñez Regueiro 1974). Sin embargo, numerosas investigaciones realizadas en los últimos años discuten los límites establecidos entre estos períodos, plantean la dificultad de su distinción en numerosos sitios arqueológicos y destacan la prolongación en el tiempo de las ocupaciones tradicionalmente asignadas a los Desarrollos Regionales (Quiroga 2011; Tarragó y Nastri 1999). Por estos motivos, en este trabajo se utilizarán las categorías "postformativo" o "prehispánico tardío" para hacer referencia al lapso temporal mencionado (Quiroga 2002).

\section{El valle del Bolsón}

El valle del Bolsón es un "valle alto" emplazado entre los 2.500 y 2.900 msm (Aschero y Korstanje 1993) (Figura 1). En virtud de su ubicación transicional entre el ambiente de puna y de valles, funcionó como zona de interacción y tránsito entre ambientes diferenciados y también fue utilizado para la explotación de recursos diversos (Aschero y Korstanje 1993). Hasta el momento no se ha recuperado evidencia incaica en la región, pero hay registros de ocupación entre los siglos XV y XVII (Quiroga 2011). La muestra cerámica analizada procede de dos asentamientos:

(1) La Angostura: asentamiento conglomerado de fácil acceso emplazado sobre los extremos de dos conos de deyección en el sector sur del valle. Las ocupaciones fueron datadas entre ca. 1460-1600 d.C. (Quiroga 2011). El sitio combina arquitectura residencial y agrícola conformada por 123 recintos que se distribuyen en sectores espacialmente discontinuos según la topografía del terreno (Quiroga 2002). Se sostiene que el carácter agregado del sitio y su diseño arquitectónico responden a una necesidad de control del agua y la tierra, recursos claves en una sociedad agrícola (Quiroga 2002). Por la envergadura del asentamiento, la baja superficie cubierta y la integración espacial de sectores agrícolas y residenciales, el sitio no evidencia la jerarquización social planteada comúnmente para el Tardío (Quiroga 2002).

(2) El Duraznito: poblado elevado de difícil acceso con características defensivas naturales emplazado en el sector central del valle (Quiroga y Martínez 2013). A partir de estas características se considera que su ubicación se relaciona con estrategias de defensa en instancias de conflictos regionales o interregionales. Los trabajos realizados hasta el momento consisten en el mapeo del sitio en su totalidad, recolecciones superficiales y realización de sondeos en los sectores residenciales y en espacios identificados funcionalmente como patios. El sitio posee 54 estructuras (Quiroga y Martínez 2013). Si bien no se dispone de fechados absolutos, se plantea que es un asentamiento vinculado a ocupaciones postformativas, debido a su emplazamiento, la planta arquitectónica y la cerámica recuperada en superficie y en excavación.

Los conjuntos cerámicos estudiados en ambos sitios proceden de excavaciones estratigráficas y recolecciones superficiales sistemáticas en recintos de ocupaciones y sectores extramuros.

\section{Cuenca del río Las Pitas}

El material procede de dos asentamientos ubicados en el curso inferior y medio de la cuenca del río Las Pitas (3.550-3.900 msm), afluente del río Punilla, colector principal de la cuenca de ANS (Figura 1):

(1) Peñas Coloradas 3 (PC3): es una peña columnar de ignimbrita ubicada en la margen E del curso inferior del río. Las ocupaciones emplazadas sobre su cumbre (PC3c) fueron intensivamente estudiadas por Cohen (2010) y datan entre ca. 810-1620 d.C. Se trata de 24 estructuras entre las que se destacan de tipo falsa bóveda, cámaras subterráneas, hondonadas, estructuras de pirca de mayores dimensiones y 13 morteros elaborados sobre la roca base. El sitio estuvo originalmente rodeado por una muralla y su acceso se encontraba restringido a un sector del perímetro. A partir del análisis del diseño arquitectónico, las relaciones espaciales y las propiedades visuales, se plantea que la diagramación del espacio construido y la elección del emplazamiento se vinculan con estrategias de ocultamiento, defensa y control visual (Cohen 2010). El material procede de recolecciones superficiales y excavaciones estratigráficas en la cumbre, recolecciones superficiales en la vega adyacente y también en la base del sitio, donde se hallaron pequeñas estructuras subterráneas que están siendo estudiadas por Cohen.

(2) Punta de la Peña 3 (PP3): se encuentra a $3 \mathrm{~km}$ al E de PC3. Consiste en una sucesión discontinua de sectores habitados caracterizados por estructuras residenciales y productivas que fueron construidas sobre la ladera de una peña de ignimbrita. Estas estructuras fueron edificadas 
aprovechando los bloques de piedras de tamaños diversos que se desprendieron de la peña por erosión (Quiroga 2012). Los estudios realizados corresponden a relevamientos planimétricos, arquitectónicos y excavaciones en los sectores B y C (Quiroga 2012; Quiroga y Cohen 2007). El sector C está conformado por cuatro recintos y el sector B por cinco. El análisis de la estratigrafía y los fechados radiocarbónicos permitieron determinar una secuencia de ocupación similar a la de PC 3c, que se inicia en el período Formativo y continúa durante el período de Desarrollos Regionales y Colonial temprano (Quiroga 2012). El material aquí analizado corresponde a las ocupaciones postformativas del Sector C y al igual que en PC3 y en el valle del Bolsón no se recuperó evidencia incaica.

\section{La Alfarería del Valle del Bolsón}

La diversidad cerámica presente en El Duraznito y en La Angostura es similar. En ambos asentamientos se establecieron grupos de referencia en los que predomina la cerámica ordinaria y pintada en negro sobre rojo (N/R) (Tabla 1, Figura 2). Esta última
Tabla 1. Grupos de referencia establecidos para el valle del Bolsón.

Bolson's pottery variability.

\begin{tabular}{lcc}
\hline $\begin{array}{l}\text { Grupos de } \\
\text { referencia }\end{array}$ & $\begin{array}{c}\text { La Angostura } \\
\text { Fragmentos: 551 }\end{array}$ & $\begin{array}{c}\text { El Duraznito } \\
\text { Fragmentos: 1.259 }\end{array}$ \\
\hline N/R & $60,55 \%$ & $36,60 \%$ \\
Ordinario & $33,63 \%$ & $49,48 \%$ \\
N/C & $5,10 \%$ & $12,89 \%$ \\
N-R-C & - & $1,03 \%$ \\
Ante & $0,72 \%$ & - \\
\hline
\end{tabular}

corresponde principalmente al estilo Belén. En menor medida se recuperaron fragmentos pintados en negro sobre crema (N/C) y negro, rojo y crema (N-R-C), algunos de ellos de estilo Santamariano y otros con diseños geométricos de bandas o líneas sinuosas como los reconocidos en los estilos Sanagasta y Abaucán. Por otra parte, hay fragmentos que no pudieron ser asignados a un estilo conocido, debido a su mal estado de conservación. De forma excepcional se recuperaron fragmentos pulidos y alisados que por su color y aspecto general se agruparon bajo la categoría "ante".

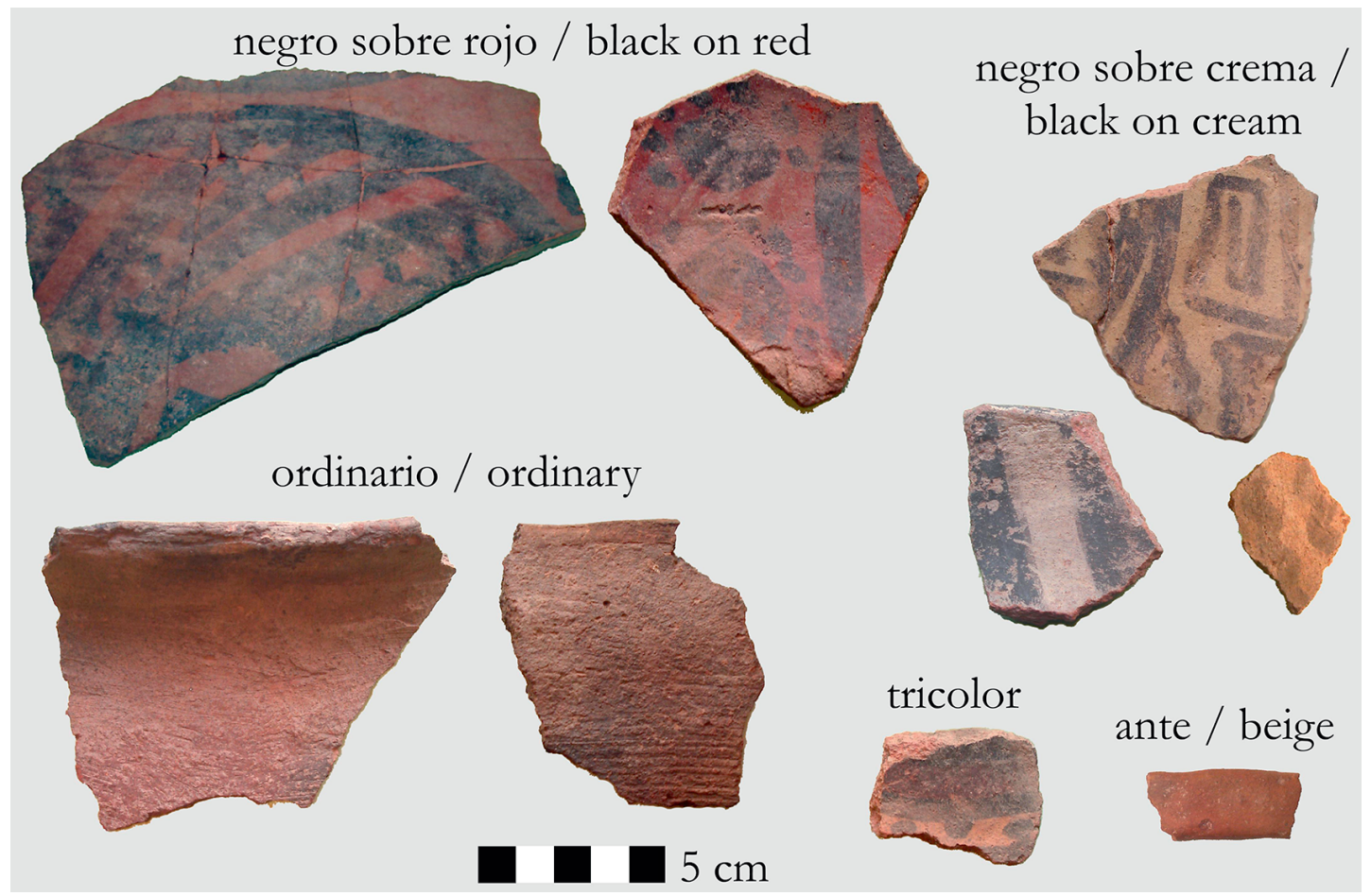

Figura 2. Grupos de referencia establecidos para el valle del Bolsón. Bolson's pottery variability. 
El conjunto Belén está presente en las tres variedades morfológicas características definidas a partir de piezas de colección: forma 1 (urna), forma 2 (puco), forma 3 (cántaro) (Puente y Quiroga 2007). A partir del material fragmentario fue posible distinguir ejemplares de contornos simples, complejos, inflexionados y angulares (Figura 3). Se trata de piezas cuyas superficies, en la mayoría de los casos, fueron pulidas. Las representaciones plásticas de este conjunto son variadas y coinciden

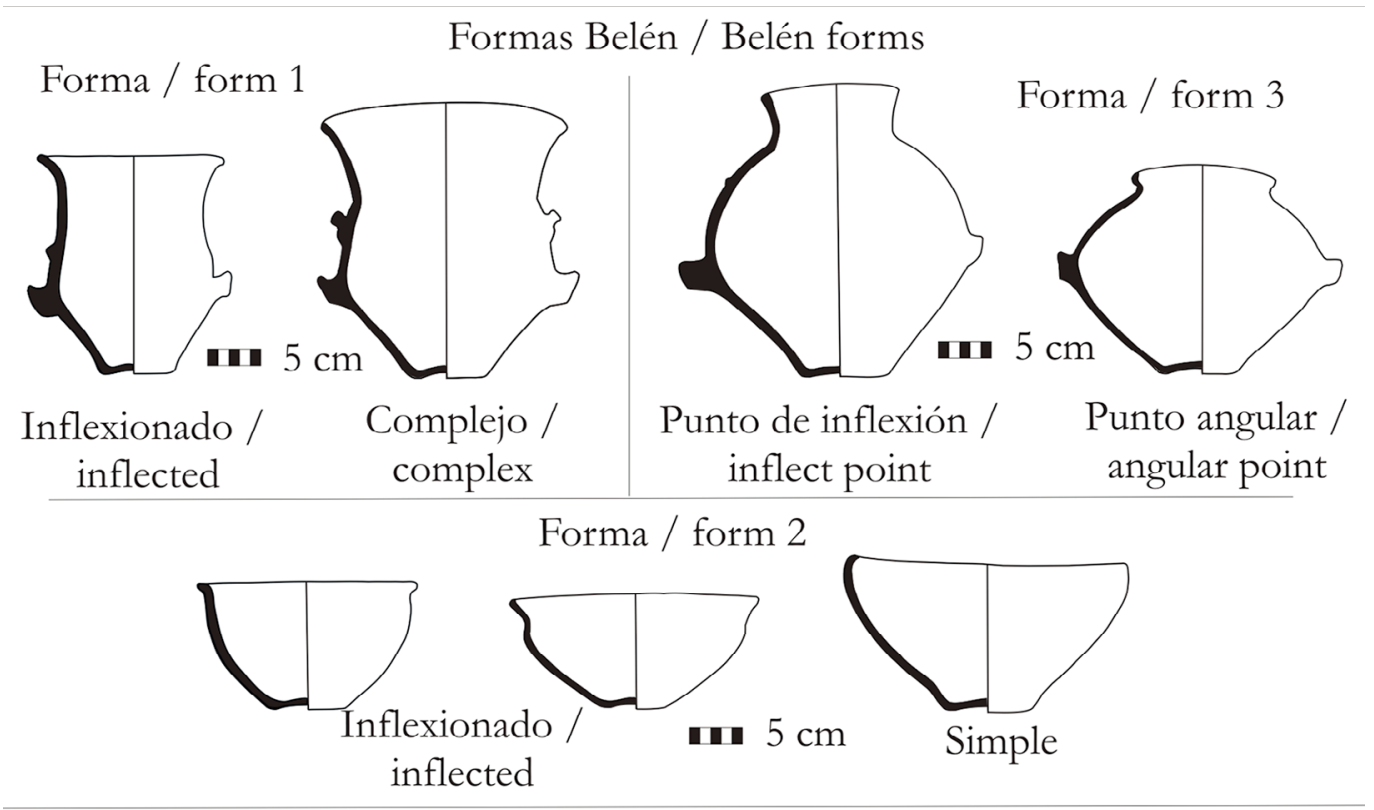

Formas ordinarias / ordinary forms
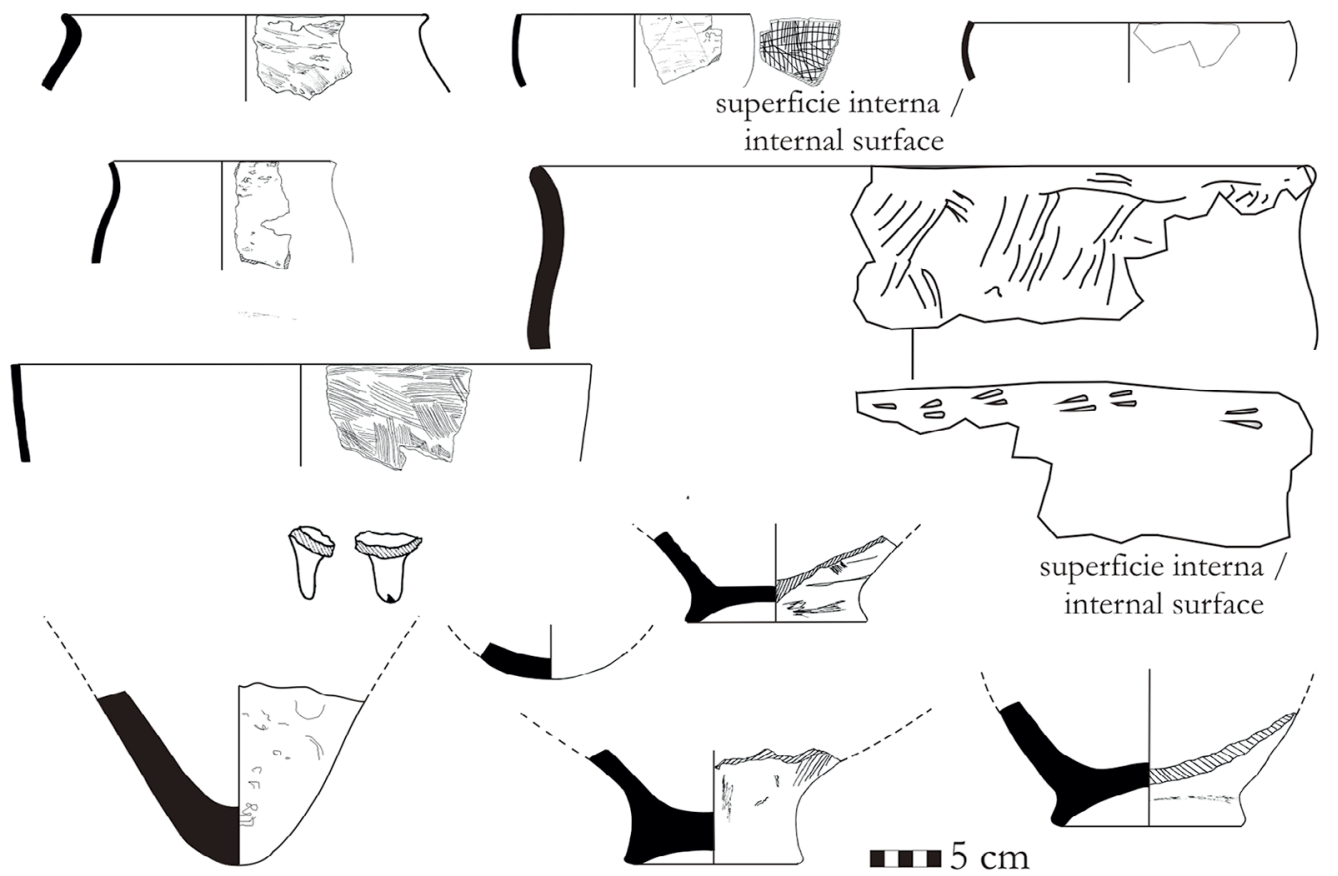

Figura 3. Diversidad morfológica Belén y ordinaria del Bolsón. Belén and ordinary morphological diversity. 
con las definidas para piezas de colección: temas geométricos y figurativos (Quiroga y Puente 2007).

El grupo ordinario corresponde a piezas con tratamientos de superficie rugosos o peinados. Las reconstrucciones morfológicas destacan que en su mayoría son vasijas de borde evertido, con cuellos cortos o sin cuello y en menor medida de borde invertido y recto. Los cuerpos varían de forma subglobular, elipsoide u ovaloide y su diámetro es superior al de la boca, el que oscila entre 13 y 54 $\mathrm{cm}$. Se distinguen bases de forma cóncava, de pie hiperboloide, trípodes y cónicas (Figura 3). Trece ejemplares poseen diseños geométricos incisos o en pastillaje ubicados en las secciones de borde, cuello o cuerpo de las piezas (Puente 2012a).

El conjunto N/C de estilo Santamariano está presente en forma de pucos y urnas. Las formas identificadas para el grupo N-R-C corresponden a pucos y piezas de forma evertida. Para el conjunto ante no fue posible reconstruir formas.

\section{Tradiciones de elaboración local}

La combinación de análisis de pastas por lupa binocular de fragmentos recuperados en ambos sitios (N: 1741) y, posteriormente, los análisis petrográficos realizados sobre ejemplares (N: 146) de cada grupo de referencia y representativos de la variabilidad de pastas previamente identificada permitieron definir dos tradiciones de manufactura predominantes en la región ${ }^{1}$ (Puente 2011). Estas se identifican a partir del tipo de antiplástico seleccionado por los alfareros para la elaboración de determinado conjunto de piezas: (1) arenas con predominio de vidrio vesicular y cuarzo junto a feldespatos y litoclastos volcánicos en el $90 \%$ de la cerámica Belén (Figura 4.A) y (2) tiesto molido o chamote en el $80 \%$ de la cerámica ordinaria (Figura 4.B), en el 86\% de los ejemplares N/C y en todos los tricolor. En la Tabla 2 se sintetiza la información.

A pesar de que cada conjunto se diferencia del otro en el tipo de temperante con el que fue manufacturado, las piezas que conforman cada uno de ellos no fueron elaboradas de forma estandarizada. Al contrario, en cada uno de estos conjuntos se reconoce diversidad en la densidad, porosidad, tamaño de las inclusiones y matriz, aspecto que refleja la coexistencia de distintos modos de elaboración de las pastas utilizadas para generar piezas similares. Esta variabilidad puede responder a distintos factores, entre ellos, el tamaño y destino de la pieza, la experiencia del alfarero, el evento de manufactura, entre otros. Sin embargo, la elección del antiplástico a utilizar para la manufactura de dichos conjuntos es compartida y atraviesa esta diversidad (Puente 2011).

Se realizaron estudios de procedencia de estos conjuntos. Estos implicaron en primer lugar estudios geológicos, muestreos de arcilla y arenas regionales y, posteriormente, estudios de AANI y petrología 2 . Los resultados obtenidos permiten sostener que
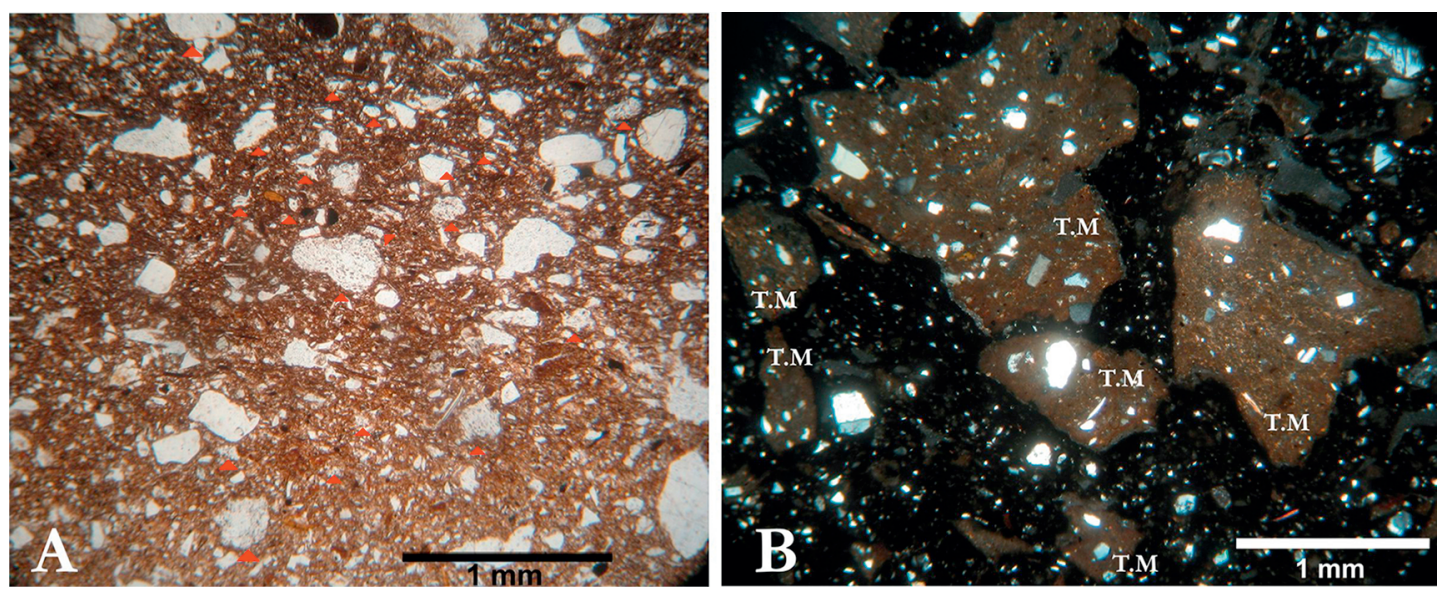

Figura 4. Fotomicrografías representativas de las dos tradiciones de elaboración. (A) vidrio vesicular y cuarzo, tomada con nicoles paralelos. Los triángulos indican el vidrio vesicular. (B) tiesto molido (TM), tomada con nicoles cruzados.

Photomicrography of the two traditions of elaboration. (A) vesicular glass and quartz, taken with parallel nicols. The triangles indicate the vesicular glass. (B) Sherd grind (TM), taken with crossed nicols. 


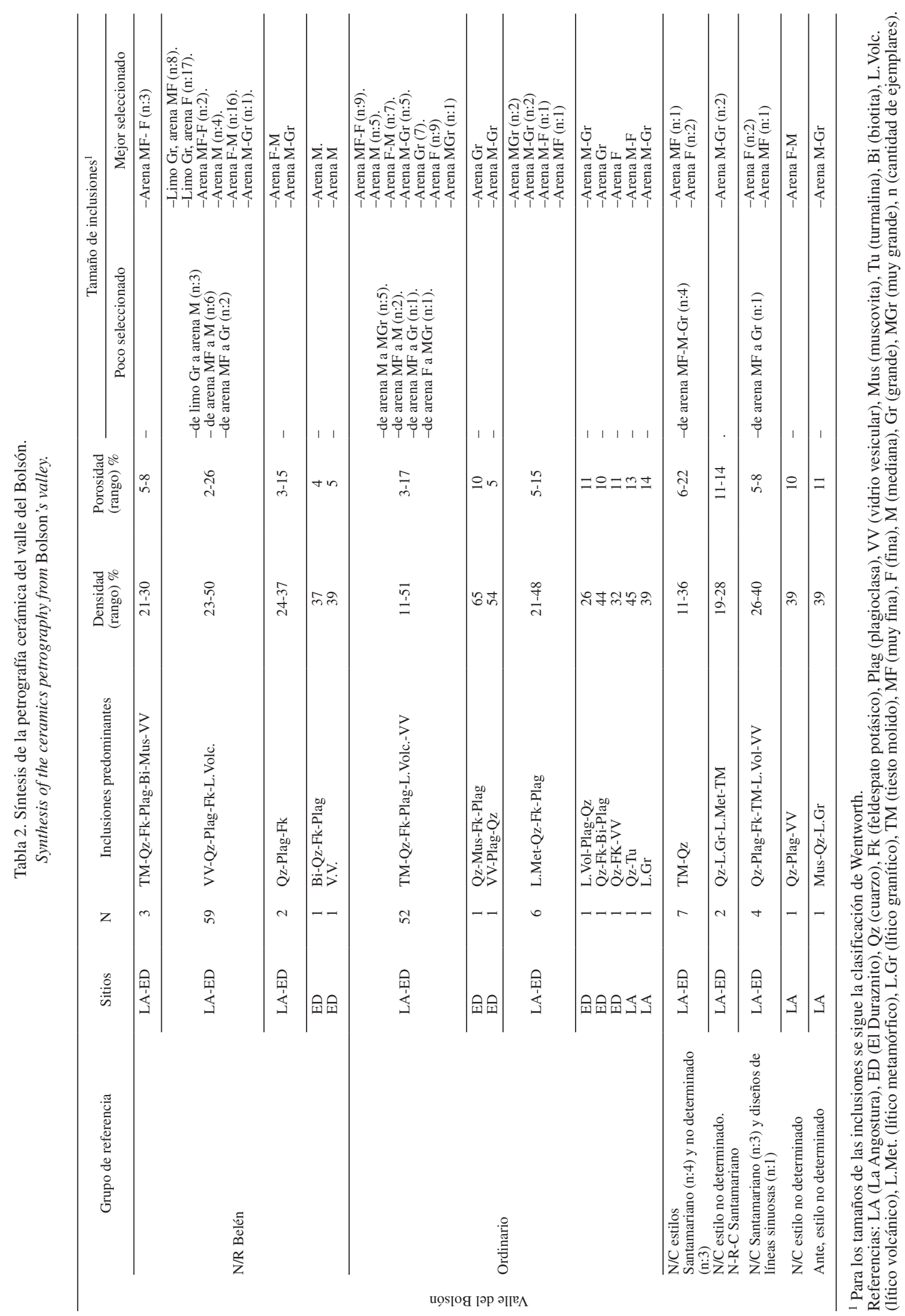


los conjuntos cerámicos predominantes (Belén y ordinario) fueron elaborados con arcillas y arenas locales (Puente 2011; Puente et al. 2014).

\section{La Alfarería del Río Las Pitas}

Debido a que los sitios de donde proceden las muestras estudiadas para la cuenca del río Las Pitas son de menor envergadura que los del valle del Bolsón, la cantidad de cerámica recuperada también es sumamente inferior. A pesar de ello, la muestra analizada es representativa de dichos asentamientos y fue obtenida en excavaciones y recolecciones superficiales intensivas.

El conjunto de PP3 es de 59 fragmentos (Tabla 3). Predomina la cerámica ordinaria con tratamientos de superficie alisados, muchos de aspecto rugoso y algunos peinados. En este conjunto, de manera excepcional, hay fragmentos que conservan engobe morado en la superficie externa. Las reconstrucciones morfológicas realizadas distinguen piezas de borde recto, recto evertido y evertido con asa labioadherida, cuerpos subglobulares y ovaloides y bases de formas cónicas y planas.

En proporciones similares entre sí se definieron los grupos de referencia N/R y N/C. A diferencia del valle del Bolsón, el conjunto N/R no se identifica con ningún estilo regional conocido. Sus superficies varían entre alisadas o pulidas y las representaciones plásticas son líneas sinuosas y rectas cruzadas. A nivel morfológico se distinguen fragmentos de dos pucos y un borde evertido. Los fragmentos N/C corresponden principalmente al cuerpo de las vasijas. Las representaciones plásticas son líneas sinuosas, chorreaduras y salpicaduras y fueron plasmadas sobre superficies alisadas. El 8,47\% de la muestra corresponde al grupo "ante". Se trata de fragmentos de cuerpo y el borde de un puco con superficies alisadas. Por último, también se recuperó un fragmento pulido sobre el que se pintaron en color negro líneas sinuosas y rectas sobre un fondo que varía entre color crema y rojizo (N-C-R).

La muestra de PC 3 es de 130 fragmentos (Tabla 3). Predomina la cerámica ordinaria de superficies alisadas rugosas o peinadas. Igual que en PP3, una pequeña muestra conserva restos de engobe morado. Se destacan fragmentos de una pieza sobre la que se plasmaron por incisión una sucesión de líneas. La reconstrucción morfológica distingue ejemplares de bordes invertidos, rectos y evertidos, cuerpos ovaloides y subglobulares y una base cónica.
Tabla 3. Grupos de referencia establecidos para Las Pitas. Las Pitas's pottery variability.

\begin{tabular}{lcc}
\hline $\begin{array}{l}\text { Grupo de } \\
\text { referencia }\end{array}$ & $\begin{array}{c}\text { PP3 } \\
\text { Fragmentos: 59 }\end{array}$ & $\begin{array}{c}\text { PC3 } \\
\text { Fragmentos: } 130 \\
\%\end{array}$ \\
\hline Ordinario & 62,72 & 65,39 \\
N/R & 15,26 & 13,08 \\
N/C & 11,86 & - \\
N-C-R & 1,69 & - \\
N/Na & - & 9,21 \\
N/Ro & - & 5,39 \\
Ante & 8,47 & 6,93 \\
\hline
\end{tabular}

En segundo lugar se distingue el grupo N/R. Algunos fragmentos pertenecieron a piezas de estilo Belén -dos pucos, posiblemente un tortero y dos urnas o cántaros-, el resto poseen representaciones plásticas de bandas y líneas geométricas. También se recuperaron fragmentos de cuerpo pintados en negro sobre naranja (N/Na), y negro sobre rosa $(\mathrm{N} /$ Ro) y un grupo denominado ante.

En síntesis, a pesar que las muestras de ambos sitios no son numerosas se destaca variabilidad (Figuras 5 y 6). Predomina el conjunto ordinario y en menor medida están presentes fragmentos correspondientes a piezas que fueron pintadas en color negro sobre fondos de distintas tonalidades. En muchos casos no es posible vincular los tiestos a estilos cerámicos conocidos. Solo parte del conjunto N/R de PC3 corresponde a piezas de estilo Belén. Los diseños pintados de bandas geométricas y líneas sinuosas son similares a los reconocidos en cerámica del área valliserrana del $\mathrm{NOA}^{3}$, entre ellos los estilos Sanagasta, Villavil y Abaucán.

\section{Materias primas y modos de elaboración}

Luego del análisis de pastas por lupa binocular (N: 189) se seleccionaron 22 ejemplares de PC3 y 9 de PP3 para estudiar con microscopio petrográfico: 11 ordinarios, $15 \mathrm{~N} / \mathrm{R}$, uno ante, uno N/Ro, uno N/ $\mathrm{Na}$, uno N-R-C y uno N/C.

Los resultados del análisis modal se presentan en la Tabla 4, donde se discriminan por sitio y grupo de referencia ${ }^{4}$. En relación con la naturaleza del temperante se destaca que:

- Solo en dos ejemplares ordinarios de PC3 (14 y 16) se utilizó tiesto molido como antiplástico. 


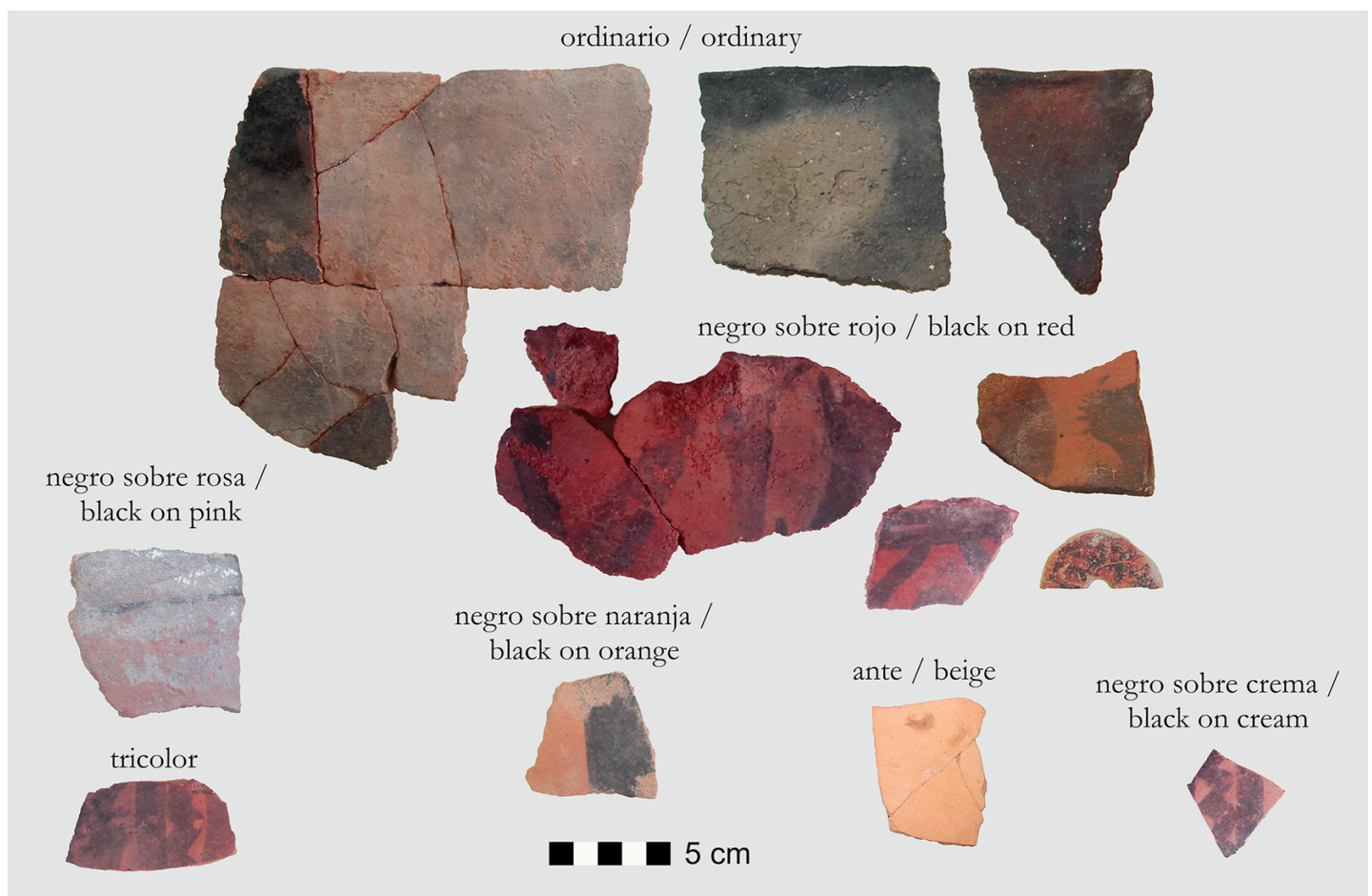

Figura 5. Grupos de referencia establecidos para Las Pitas. Las Pitas's pottery variability.

Formas ordinarias / ordinary forms

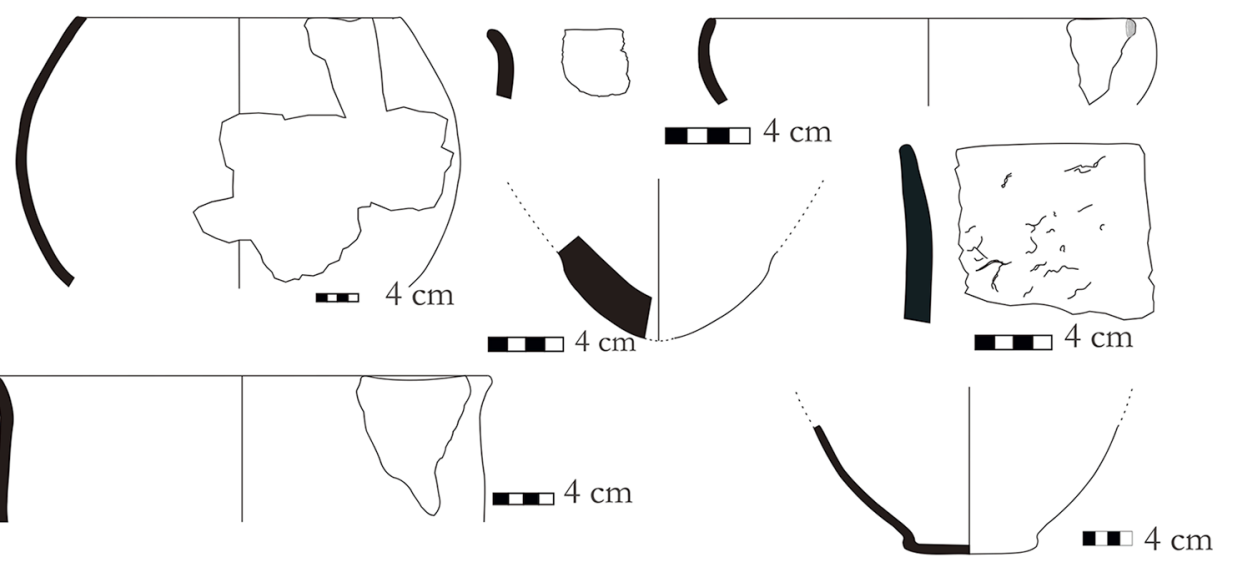

Formas ante / beige forms

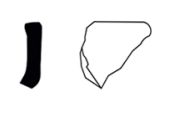

a

$4 \mathrm{~cm}$

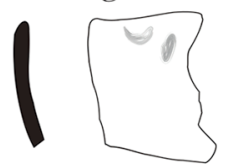

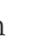

gro sobre crema /

on cream 


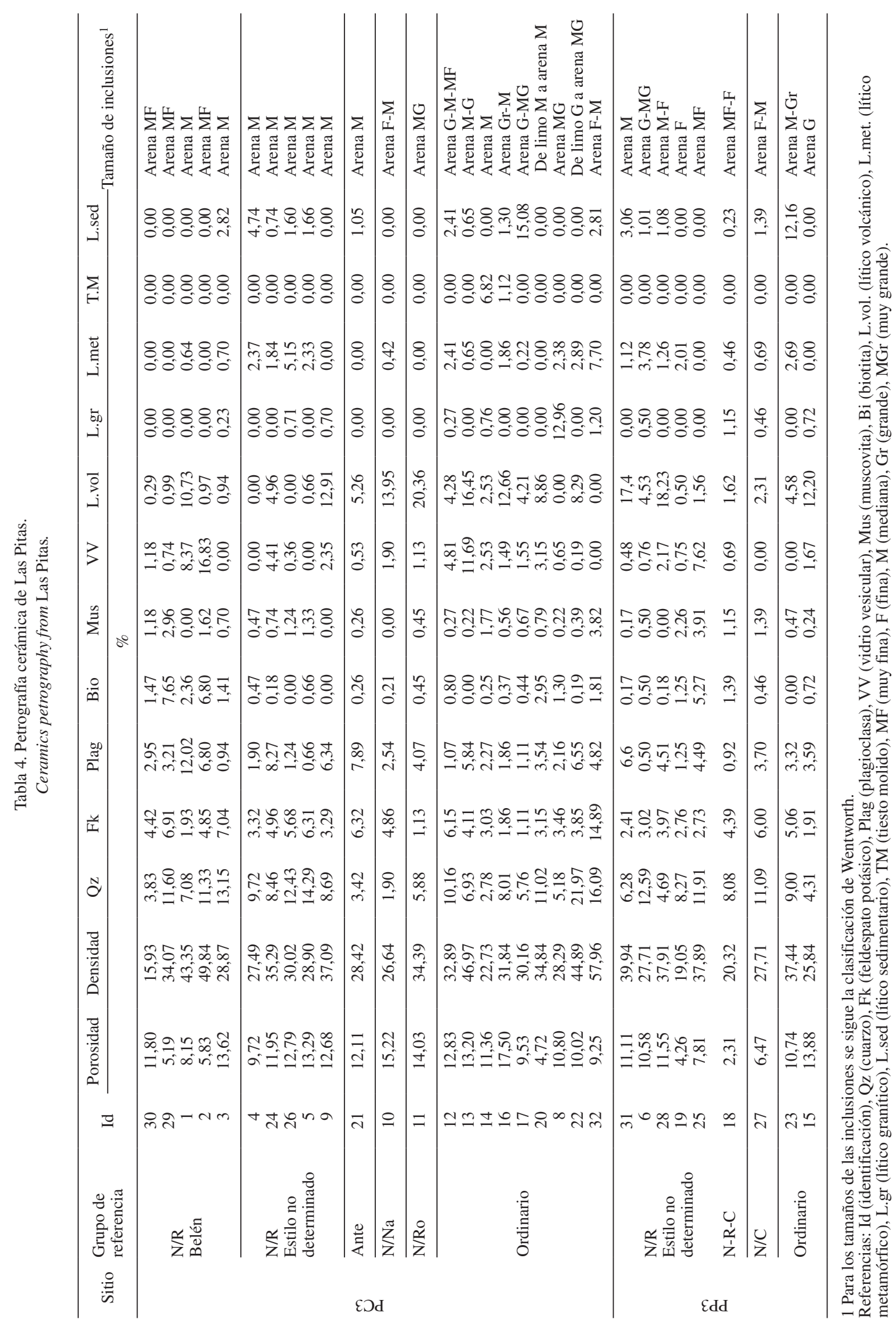


Uno de ellos corresponde a una pieza sobre la que se plasmaron representaciones plásticas incisas sobre la superficie externa (Figura 7H).

- La mayoría de las pastas poseen clastos de origen volcánico: fragmentos de roca, vidrio, plagioclasas zonadas y cuarzo monocristalino. Sin embargo, no todas las pastas son iguales, sino que se establecen las siguientes agrupaciones según el tipo de antiplástico predominante:

A- litoclastos volcánicos, cuarzo, feldespato (plagioclasa y/o feldespato potásico), vidrio vesicular. Ejemplares 1-13-9-31-28-11-15-10-2021-24 (Figura 7A).

B- cuarzo, feldespato potásico. Ejemplares 3, $5,18,27,19,26,4,22,12,29$ y 30 (Figura 7B)

C- cuarzo, vidrio vesicular. Ejemplares 2 y 25 (Figura 7C).

D- litoclastos sedimentarios y cuarzo. Ejemplares 17 y 23 (Figura 7D).
E- cuarzo, feldespato potásico, lítico metamórfico. Ejemplar 26 (Figura 7E).

F- cuarzo, lítico volcánico, lítico metamórfico, feldespato potásico. Ejemplar 6 (Figura 7F).

G- litoclastos graníticos. Ejemplar 8 (Figura 7G).

Esta variedad composicional indica la ausencia de un patrón en las materias primas usadas para manufacturar cada grupo de referencia y para cada sitio. También se destaca diversidad en los modos de elaboración de las pastas evidenciado en la densidad, porosidad y tamaño de las inclusiones.

Los estudios de procedencia de estos conjuntos se encuentran en proceso de análisis. Geológicamente la región es primordialmente volcánica. El área de estudio presenta numerosos afloramientos tabulares de ignimbritas producto de erupciones efusivas del volcán Galán. Estos farallones son de textura porfídica con fenocristales de plagioclasas, cuarzo y biotita (Atlas Catamarca; Cohen 2010). Con el
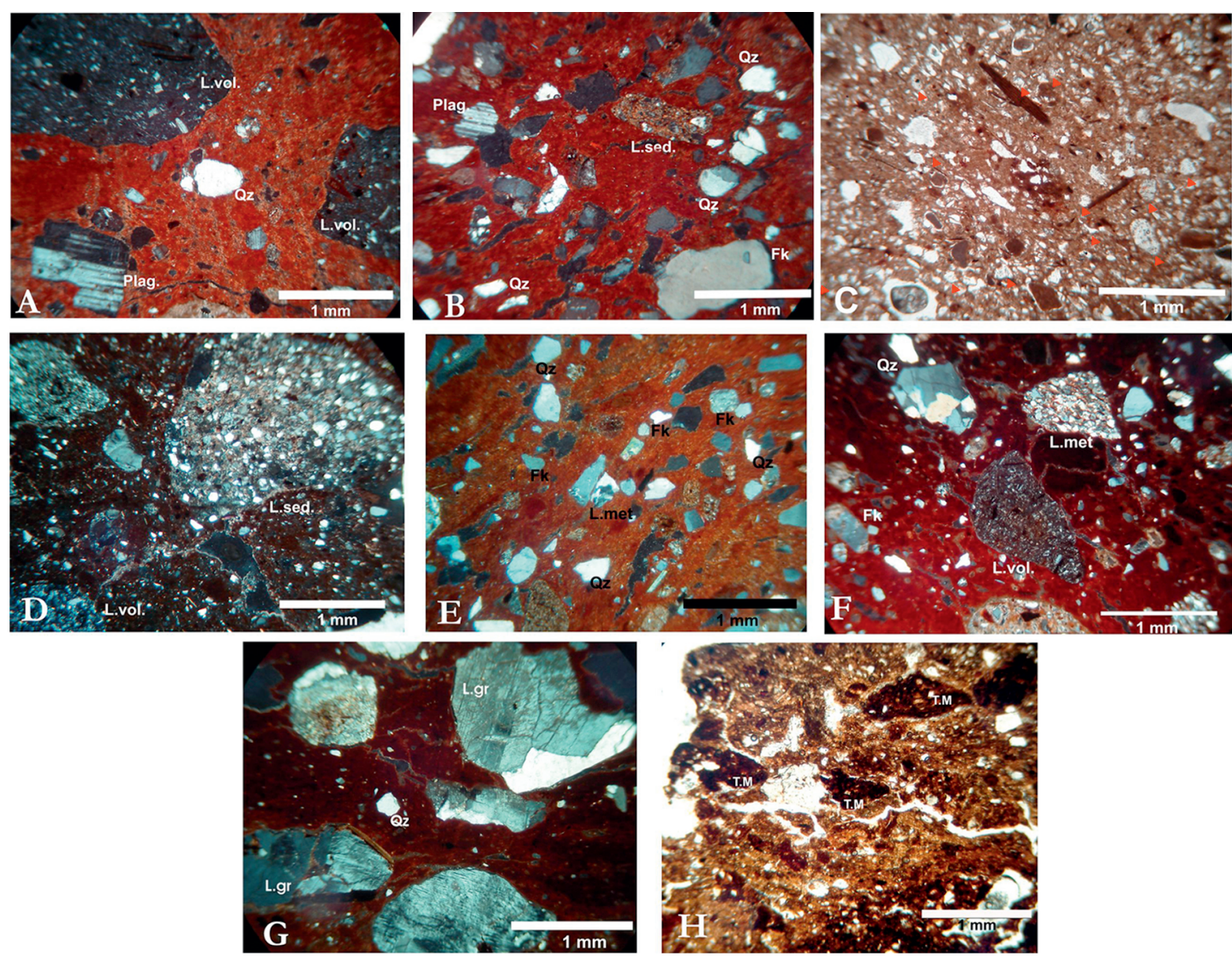

Figura 7. Fotomicrografías de pastas: con nicoles cruzados (A, B, D, E, F, G), con nicoles paralelos (C y H). Los triángulos en C indican el vidrio vesicular.

Photomicrography of paste: with crossed nicols $(A, B, D, E, F, G)$, with crossed nicols $(C$ y $H)$. The triangles in $C$ indicate the vesicular glass. 
objetivo de obtener información precisa sobre la composición de las arenas regionales y de comparar con la naturaleza de las inclusiones de la cerámica (estudios petrológicos) se realizó un muestreo regional. Hasta el momento se cuenta con el estudio petrográfico de cuatro arenas, tres de ellas de distintos puntos a lo largo del cauce del río Las Pitas y una de la base del volcán La Alumbrera, ubicado en el fondo de cuenca de Antofagasta. Excede los límites del trabajo presentar en profundidad estos resultados, sin embargo cabe mencionar que el predominio de componentes volcánicos se destaca en todas las muestras. Asimismo, se reconocen particularidades en cada uno de los depósitos, ya que algunos poseen bajos porcentajes metamórficos y sedimentarios. La comparación preliminar entre estas muestras y la cerámica permite pensar que los grupos composicionales mencionados en párrafos anteriores (excepto el $\mathrm{G}$ ) son el resultado de la utilización de diferentes fuentes de temperante local. Igualmente, la información es aún escasa para establecer conclusiones precisas.

\section{Formas, Colores y Pastas: Similitudes y Diferencias entre Ambas Regiones}

Los alfareros son actores sociales que eligen cómo hacer sus piezas, qué materias primas usar y qué aspecto darles. Dichas elecciones conforman un "saber hacer" particular que se reproduce, en parte, de forma consciente e inconsciente pero a partir del cual los artesanos se identifican a sí mismos y se diferencian de otros (Gosselain 1998; Lemonnier 1992). Esta combinación de elecciones y su producto final-el objeto elaborado- tienen su propia historia, ya que son el resultado de conocimientos adquiridos con la enseñanza, copia o invención y, combinados adquieren un nuevo significado. De este modo, los objetos cerámicos constituyen un ítem material que estudiado de manera holística -estética, tecnología y materias primas- brinda evidencia sobre elecciones realizadas en distintas etapas del proceso de producción y, en este sentido, permite abordar la problemática de la interacción a distintas escalas y evaluar la circulación de objetos y saberes. Por ejemplo, a) la existencia o no de tradiciones de manufactura compartidas entre alfareros de una misma comunidad brinda información sobre formas de interacción local; b) el análisis comparativo de alfarería procedente de regiones distantes pero interrelacionadas brinda elementos para discutir las modalidades que adquirió dicha interacción, dando cuenta si circularon las piezas terminadas o ciertos conocimientos sobre cómo elaborarlas o qué apariencia final darles.

El caso particular aquí estudiado, la interacción entre ANS y los valles del oeste catamarqueño, se evidencia por múltiples materialidades: recursos líticos, iconografía, estilos cerámicos, arquitectura, etc. Este trabajo presenta los primeros aportes al tema desde el estudio comparativo y de abordaje holístico de la alfarería del valle del Bolsón y la cuenca del río Las Pitas y constituye un avance preliminar para evidenciar la coexistencia de formas de circulación variadas entre grupos sociales que habitaron ambientes de producción diferenciada durante el tardío prehispánico. Si bien es necesario ampliar la muestra analizada y se requieren estudios de procedencia para los conjuntos de ANS, la información generada permite concluir que la cerámica de ambas regiones posee similitudes y diferencias que demuestran la circulación de ciertas piezas y de ideas materializadas en estilos cerámicos, recursos estilísticos y patrones estéticos. En cambio, las tradiciones de manufactura identificadas para el Bolsón no se replican en Las Pitas.

En el Bolsón predominan los conjuntos ordinarios y Belén. A diferencia de Las Pitas donde hay mayor variabilidad a pesar de tratarse de muestras menos numerosas: predomina la cerámica ordinaria y N/R, pero solo una parte se reconoce como Belén. Se identificaron diseños geométricos pintados en negro sobre fondo rojo y en menor medida negro sobre crema reproducidos en otros estilos regionales, por ejemplo Sanagasta, Villavil y Abaucán. Si bien no es posible realizar una asociación estilística concreta se destaca que los recursos de uso del color (principalmente negro y rojo), las representaciones plásticas (líneas sinuosas, bandas de líneas rectas cruzadas) y las técnicas plásticas (la pintura) son compartidos entre Las Pitas y numerosos valles del oeste catamarqueño. Sin embargo, los habitantes de Las Pitas no evidencian hasta el momento "identificarse" con un estilo regional particular definido para el área valliserrana del NOA.

Respecto de las materias primas, la cerámica Belén del Bolsón fue elaborada con altos porcentajes de cuarzo y vidrio vesicular -entre otros clastos líticos y minerales- y conforma una clara tradición de manufactura producida en la región (Puente 2011, 2012b). En Las Pitas hay dos ejemplares de 
este estilo -un puco y una urna- que se asemejan en la composición a dicha cerámica. En el resto, el vidrio está ausente o presente en escasos porcentajes. Si bien es necesario realizar análisis de AANI para discutir con mayor precisión la procedencia de los conjuntos, se propone que las piezas de petrografía similar proceden del valle del Bolsón o zonas lindantes como Hualfín donde las pastas son semejantes, a diferencia del resto que hasta el momento no se descarta su producción local debido a la similitud petrográfica con las arenas analizadas. Tampoco se puede descartar que estos ejemplares procedan del sector de fondo de cuenca de ANS, donde en sitios como Bajo del Coypar II y La Alumbrera la cerámica Belén representa porcentajes sumamente altos (Vigliani 1999; Olivera et al 20032005). Igualmente, hasta el momento no se cuenta con antecedentes de estudios petrográficos y de procedencia para dicho sector de la microrregión.

En relación con la cerámica ordinaria, si bien en el Bolsón las muestras son más numerosas y se reconoce mayor variabilidad que en Las Pitas, las formas reconstruidas en ambas regiones se perciben como similares. Entre ellas se destacan vasijas subglobulares u ovaloides con base cónica, bordes evertidos e invertidos, tratamientos de superficie rugosos y peinados. A pesar de estas semejanzas en la estética visual, las tradiciones de manufactura utilizadas fueron diferentes: con chamote en el Bolsón y sin él en Las Pitas. El uso de este antiplástico responde a una tradición de amplia dispersión en el área valliserrana (Puente 2012a). Sin embargo, en la muestra estudiada para ANS solo se identificó de forma excepcional en dos ejemplares ordinarios, uno de ellos con líneas incisas en la superficie externa. A causa de que ambos aspectos - chamote y diseños incisos-se registran en vasijas ordinarias halladas en los valles del Bolsón y aledaños (Hualfín y Yocavil), posiblemente esta pieza haya circulado desde alguno de los valles mencionados hacia la puna. Asimismo, los estudios macroscópicos de pastas disponibles para la cerámica de Bajo del Coypar II evidencian ejemplares ordinarios elaborados con tiesto molido (Vigliani 1999), razón por la que los dos ejemplares mencionados para Las Pitas pueden haber circulado desde los valles mencionados o desde el fondo de cuenca de ANS.

A partir de estos resultados concluyo de forma preliminar que las principales semejanzas entre la cerámica de Las Pitas y el Bolsón se establecen en la estética visual de las piezas y no en sus pastas, y sugiero como hipótesis que los alfareros de Las Pitas elaboraron su cerámica combinando recursos estilísticos de la alfarería elaborada en el área valliserrana (formas, colores, tratamientos de superficie, representaciones y técnicas plásticas), pero con materias primas locales y modos de hacer particulares. En este sentido, ¿reelaboraron en términos propios lo que ven circular? Para responder este interrogante es necesario avanzar con los estudios de procedencia para definir las tradiciones de elaboración local en ANS y ello requiere profundizar los estudios petrológicos y vincularlos con AANI.

Por último, si analizamos la cerámica de la microrregión de ANS como conjunto se destacan diferencias importantes entre las distintas sectorizaciones ambientales. Los resultados obtenidos hasta el momento en dos sectores intermedios de ANS -río Las Pitas y Miriguaca- son similares: predomina la cerámica ordinaria, no se incorporó tiesto molido en las pastas y el estilo Belén apenas está presente (Gasparoti 2012). Ambas regiones se diferencian con el fondo de cuenca de ANS, donde la cerámica Belén prevalece entre los conjuntos hallados, hay considerables porcentajes de cerámica Santamariana e incaica y el chamote es característico en la cerámica ordinaria (Vigliani 1999). De este modo, y en concordancia con lo planteado por Gasparoti (2012), la alfarería de los sectores intermedios respondería a lógicas de manufactura diferente e incluso a estilos distintos que los identificados para el fondo de cuenca de ANS. Esta diferenciación entre sectores intermedios y fondo de cuenca se ha detectado también en otras líneas de evidencia-modalidades constructivas, formas de emplazamiento, instrumental lítico, etc.-, a partir de las que se sostiene la coexistencia de formas de organización social diferentes en la microrregión. Concretamente en Las Pitas perduraron unidades sociales autónomas con prácticas de producción y reproducción social con modalidades propias y diferentes a las del fondo de cuenca (Cohen 2010, 2014).

En síntesis, este trabajo expone los primeros aportes desde la alfarería al estudio de las relaciones de interacción entre un sector intermedio de ANS y el valle del Bolsón en el segundo milenio de la era. Los resultados alcanzados constituyen un avance preliminar para evidenciar la coexistencia de formas de circulación variadas -bienes y saberes- entre grupos sociales que habitaron regiones distantes. 
Asimismo, se destaca la variabilidad de relaciones y contextos sociales existentes tanto entre distintos sectores de ANS -fondo de cuenca y sectores intermedios-como entre ellos y el área valliserrana, tema que requiere de un profundo análisis.
Agradecimientos: Este trabajo fue financiado por: ANCYT-PICT 1657 y PIP-CONICET 112200801-00285. Se agradece a los evaluadores anónimos por sus comentarios y sugerencias, los que han contribuido a mejorar el trabajo.

\section{Referencias Citadas}

Acuto, F. 2007. Fragmentación vs. integración comunal: repensando el período tardío del Noroeste Argentino. Estudios Atacameños 34:71-95.

Aschero, C. 2000. Figuras humanas, camélidos y espacios en la interacción circumpuneña. En Arte en las Rocas. Arte Rupestre, Menhires y Piedras de Colores en Argentina, editado por M. Podestá y M. De Hoyos, pp. 15-44. SAA y A. A. INAPL, Buenos Aires.

Aschero, C. y M.A. Korstanje 1993. About human figures, production and symbols. Some aspects of Northwestern Argentine Rock Art. Valcamonica Symposium ‘93, pp. 1-15. Centro Camuno di Studi Preistorici, Italia.

Atlas Catamarca, 2009. http://www.atlas.catamarca.gov.ar. (14 de diciembre).

Bauer, A. y A. Davis 2010. Rethinking Trade as a Social Activity: An Introduction. En Social Archaeologies of Trade and Exchange: Exploring Relationships Among People, Places and Things, editado por A. Bauer y A. Davis, pp. 13-48. Left Coast Press, Walnut Creek.

Cohen, L. 2010. Jerarquías, Estrategias de Control y su Espacialidad. Perspectivas desde el Sitio Peñas Coloradas 3 Cumbre (Antofagasta de la Sierra, Catamarca). Tesis doctoral, FFyL, Universidad de Buenos Aires, Buenos Aires.

Cohen, L. 2014. Miradas desde y hacia los lugares de poder. Antofagasta de la Sierra entre ca 1000 y 1500 años DC (25 de junio). https://sites.google.com/site/reviarqueol4/home/ arqueologa-20-1-2014 (26 de junio).

Cremonte, M.B. 1996. Investigaciones Arqueológicas en la Quebrada de la Ciénaga (Dpto. Tafí, Tucumán). Tesis doctoral, FCNyM, Unversidad Nacional de La Plata, La Plata.

Elías, A. y P. Escola 2010. Viejos y nuevos horizontes: obsidianas entre las sociedades agrícolas-pastoriles del Período Tardío en Antofagasta de la Sierra (provincia de Catamarca, Puna Meridional Argentina). Revista Española de Antropología Americana 40:9-29.

Gasparotti, L. 2012. Tecnología Cerámica y Producción Alfarera Durante el Período Tardío en Antofagasta de la Sierra (Prov. de Catamarca). Tesis de licenciatura, Escuela de Arqueología, Universidad Nacional de Catamarca, Catamarca.

Gell, A. 1998. Art and Agency. An Anthropological Theory. Clarendon Press, Oxford.

Gosden, C. 2001. Making sense: archaeology and aesthetics. World Archaeology 33:163-167.

Gosselain, O.P. 1998. Social and Technical Identity in a Clay Crystal Ball. En Social Boundaries on the Sepik Coast of New
Guinea, editado por M. Stark, pp. 78-106. Smithsonian Institution Press, Washington.

Jones, A. 2002. Archaeological Theory and Scientific Practice. Cambridge University Press, London.

Lazzari, M. 1999. Distancia, espacio y negociaciones tensas: el intercambio de objetos en arqueología. En Sed Non Satiata, Teoría Social en Arqueología Latinoamericana Contemporánea, editado por A. Zarankin y F. Acuto, pp. 177-152. Ediciones del Tridente, Buenos Aires.

Lemonnier, P. 1992. Elements for an Anthropology of Technology. Museum of Anthropology, Michigan.

Nielsen A. 2001. Evolución social en Quebrada de Humahuaca (AD 700-1536). En Historia Argentina Prehispánica, editado por E. Berberián y A. Nielsen, pp. 171-264. Editorial Brujas, Córdoba.

Nielsen, A. 2006. Pobres jefes: aspectos corporativos en las formaciones sociales pre-inkaicas de los Andes Circumpuneños. En Contra la Tiranía Tipológica en Arqueología. Una Visión desde Sudamérica, editado por C. Gnecco y C.H. Langebaek, pp. 120-150. Uniandes-Ceso, Colombia.

Núñez, L. y T. Dillehay 1979. Movilidad Giratoria, Armonía social y Desarrollo en los Andes Meridionales: Patrones de Tráfico e Interacción Económica. Universidad Católica del Norte, Antofagasta.

Núñez Regueiro, V. 1974. Conceptos instrumentales y marco teórico en relación al análisis del desarrollo cultural del noroeste argentino. Revista del Instituto de Antropología V:169-190.

Olivera, D., S. Vigliani, A. Elías, L. Grana y P. Tchilinguirian 2003-2005. La ocupación tardío-inka en la Puna meridional: el sitio Campo Cortaderas. Cuadernos del INAPL 20:257-277.

Podestá, M. y D. Olivera 2006. El contexto ecológico y económico del arte rupestre en la arqueología de la Puna Meridional Argentina. En Kay Pacha.Cultivating Earth and Water in the Andes (BAR International Series 1478), editado por P. Dransart, pp. 137-149. Archaeopress, Oxford.

Puente, V. 2011. Prácticas de Producción Alfarera en el Valle del Bolsón (Belén, Catamarca). Materias primas y Modos de Hacer ca. 900-1600 d.C. Tesis Doctoral, FFyL, Universidad de Buenos Aires, Buenos Aires.

Puente, V. 2012a. "Atravesando fronteras": prácticas e identidades sociales compartidas durante el tardío prehispánico en el área valliserrana del NOA. Una discusión desde la alfarería ordinaria del valle del Bolsón. Relaciones de la SAA XXXVII:65-87.

Puente, V. 2012b. Lo que oculta el estilo: materias primas y modos de elaboración de alfarería Belén. Una discusión desde 
la petrografía de conjuntos cerámicos del Valle del Bolsón (Belén, Catamarca, Argentina). Estudios Atacameños 43:71-94.

Puente, V. y L. Quiroga 2007. Percepción de la forma, variabilidad del conjunto estilístico Belén (colección Schreiter). Mundo de Antes 5:157-184.

Puente, V., R. Plá y R. Invernizzi 2014. La alfarería del tardío prehispánico del valle del Bolsón (Catamarca, Argentina): ¿Producción local o alóctona? Revista del Museo de Antropología 7:71-94.

Quiroga, L. 2002. Paisaje y Relaciones Coloniales en el Valle de Cotahau. Del Tardío a la Ocupación Colonial. Tesis Doctoral, Facultad de Geografía e Historia, Universidad de Sevilla, Sevilla.

Quiroga, L. 2011. Al Abrigo de sus Huaycos: Narrar la geografía, habitar los espacios, interpretar las prácticas. En Sociedades Precolombinas Surandinas, editado por M. E. Albeck, B. Cremonte y M. Ruiz. UNJU, en prensa.

Quiroga, L. 2012. En aquellas peñas: Espacios habitados en contexto colonial (Punta de la Peña, Antofagasta de la Sierra, Catamarca, Argentina). En Arqueología del Contacto en América Latina, editado por S. Allen y N. Moragas Segura, en prensa.

Quiroga, L. y L Cohen 2007. Múltiples espacios... una misma peña. Diseño arquitectónico y emplazamiento en sitios tardíos. Punta de la Peña, Antofagasta de la Sierra, Catamarca. Ponencia presentada en el XVI Congreso Nacional de Arqueología Argentina, Jujuy.

Quiroga, L. y S. Martínez 2013. Vivir en los cerros. Arquitectura y entorno en el Valle del Bolsón ScaBe 4(2): La Peña del Corral o El Duraznito. Ponencia presentada en el XVIII Congreso Nacional de Arqueología Argentina, La Rioja.
Quiroga, L. y V. Puente 2007. Imagen y percepción: iconografía de las urnas Belén. Colección Schreiter. En Producción y Circulación Prehispánicas de Bienes en el Sur Andino, editado por A. Nielsen, M.C. Rivolta, V. Seldes, M.M. Vázquez y P.H. Mercolli, pp. 323-346. Editorial Brujas, Córdoba.

Raffino, R. y E. Cigliano 1973. La Alumbrera: Antofagasta de la Sierra. Un modelo de ecología cultural prehispánica. Relaciones de la SAA 7:241-258.

Shanks, M. y C. Tilley 1987. Social Theory and Archaeology. Polity Press, Oxford.

Shepard, A. 1957. Ceramics for the Archaeologist. Carnegie Institution of Washington, Washington DC.

Stoltman, J. B. 2001. The rol of petrography in the study of archaeological ceramics. En Earth Sciences and Archaeology, editado por P. Goldberg, V.T. Holliday y C. Reid Ferring, pp. 297-326. Kluwer Academic, Plenum Publishers, New York.

Tarragó, M. 2000. Chacras y pukará. Desarrollos sociales tardíos. Nueva Historia Argentina, pp. 257-301. Sudamericana, Buenos Aires.

Tarragó, M. N., L. González y J. Nastri 1997. Interacciones prehispánicas a través del estilo: el caso de la iconografía Santamariana. Estudios Atacameños 14:223-242.

Tarragó, M. y J. Nastri 1999. Dimensiones de la complejidad santamariana. Actas XII Congreso Nacional de Arqueología Argentina, Tomo II, pp. 259-264.

Vigliani, S. 2005. El sitio Bajo de Coypar II: las evidencias más tempranas (ca. 1000 AP) del proceso agropastoril en la Puna Meridional Argentina (Antofagasta de la Sierra, Catamarca). Andes 16:325-350.

\section{Notas}

1 Los análisis morfológicos y petrográficos detallados pueden consultarse en Puente (2011, 2012a, 2012b).

2 Los datos precisos de esta etapa de investigación pueden consultase en Puente (2011)

3 Área conformada por un conjunto de valles y quebradas (entre los 1.500 y $3.000 \mathrm{msm}$ ) emplazados en las provincias de Catamarca, La Rioja, norte de San Juan, oeste de Tucumán y el oeste de Salta.

4 Por una cuestión de espacio, en la Tabla se muestran solo los tipos de antiplásticos más representados. 
